OPEN ACCESS

Edited by:

Franco Andreone,

Museo Regionale di Scienze

Naturali, Italy

Reviewed by:

Giovanni Amori,

Italian National Research Counci

(CNR), Italy

Giuseppe Bogliani,

University of Pavia, Italy

*Correspondence:

Emiliano Mori

moriemiliano@tiscali.it

†These authors have contributed equally to this work

Specialty section This article was submitted to

Conservation,

a section of the journal

Frontiers in Ecology and Evolution

Received: 02 May 2019 Accepted: 25 November 2019 Published: 13 December 2019

Citation:

Mori E, Menchetti M, Camporesi A Cavigioli L, Tabarelli de Fatis $K$ and Girardello M (2019) License to Kill? Domestic Cats Affect a Wide Range of

Native Fauna in a Highly Biodiverse Mediterranean Country.

Front. Ecol. Evol. 7:477.

doi: 10.3389/fevo.2019.00477

\section{License to Kill? Domestic Cats Affect a Wide Range of Native Fauna in a Highly Biodiverse Mediterranean Country}

\author{
Emiliano Mori ${ }^{1 * t}$, Mattia Menchetti ${ }^{2,3+}$, Alberto Camporesi ${ }^{4}$, Luca Cavigioli ${ }^{5}$, \\ Karol Tabarelli de Fatis ${ }^{6}$ and Marco Girardello ${ }^{7}$ \\ ${ }^{1}$ Dipartimento di Scienze della Vita, Università degli Studi di Siena, Siena, Italy, ${ }^{2}$ Institut de Biologia Evolutiva, Consejo \\ Superior de Investigaciones Cientificas - Universitat Pompeu Fabra, Barcelona, Spain, ${ }^{3}$ Dipartimento di Biologia, Università di \\ Firenze, Sesto Fiorentino, Italy, ${ }^{4}$ Associazione per la Divulgazione Ambientale e Scientifica, Dovadola, Italy, ${ }^{5}$ Società di \\ Scienze Naturali del Verbano Cusio Ossola, Museo di Scienze Naturali, Collegio Mellerio Rosmini, Domodossola, Italy, \\ ${ }^{6}$ MUSE - Museo delle Scienze, Corso del Lavoro e della Scienza, Trento, Italy, ${ }^{7}$ cE3c-Centre for Ecology, Evolution and \\ Environmental Changes/Azorean Biodiversity Group and Universidade dos Açores, Faculty of Agriculture and Environment, \\ Angra do Heroísmo, Portugal
}

Amongst domestic animals, the domestic cat, Felis catus, is widely considered to be one of the most serious threats to wildlife conservation. This is particularly evident for island ecosystems, as data for mainland countries are often lacking. In Italy, the European country that is richest in biodiversity, cats are very popular pets. In this work, we aimed at assessing the potential spectrum of wild vertebrates that may be killed by free-ranging domestic cats, and we considered our results within the context of their conservation status and IUCN threat category. We collected data on the impact of cats both through a citizen science approach (wildlife predations by 145 cats belonging to 125 owners) and by following 21 of these 145 cats for 1 year and recording all of the prey they brought home. Domestic cats may kill at least 207 species (2042 predation events) in Italy; among those, 34 are listed as "Threatened" or "Near Threatened" by the IUCN and Italian Red Lists. Birds and mammals such as passerines and rodents were reported to be the groups most commonly killed by free-ranging cats. When considering this diet in functional trait space, we observed that the class occupying the largest functional space was that of birds, followed by mammals, reptiles, and amphibians. Thus, the largest impact was on the functional structure of mammal and bird communities. The use of a collar bell did not affect the predation rate of cats, and the number of prey items brought home decreased with increasing distance from the countryside. We provided strong evidence that free-ranging domestic cats may seriously affect the conservation of threatened and non-threatened wildlife species, which are already suffering from population declines due to other causes, e.g., habitat loss. The mitigation of the impacts of domestic cats on wildlife requires dissemination projects promoting responsible cat ownership, as well as a restriction of free-ranging behavior, particularly at nighttime.

Keywords: Felis catus, alien species impacts, responsible pet ownership, predation rate, feral species 


\section{INTRODUCTION}

Understanding the processes shaping ecological communities under multiple disturbances is a crucial challenge in ecology and conservation biology (e.g., Davis et al., 2000; Cilleros et al., 2016; Mazel et al., 2017). Biological invasions represent a serious threat to global biodiversity at all organization levels, from genes to ecosystems (Wonham, 2006). By definition (Wonham, 2006), domestic species should also be considered "alien" when they establish free-ranging populations in the wild outside their native range (Carthey and Banks, 2012; Home et al., 2017; Boano et al., 2019). The presence of domestic freeranging animals may disrupt ecosystems or contribute to local extinction events (Malo et al., 2011). The impacts of feral pets include environmental/habitat alterations (e.g., rabbits: Flux and Fullagar, 1992; pigeons: Boano et al., 2019), predation of native fauna (e.g., cats: Loss et al., 2013; dogs: Doherty et al., 2017), hybridization with related wild species (e.g., ferrets: Davison et al., 1999; cats: Randi et al., 2001; dogs: Bassi et al., 2017), and disease transmission (e.g., ducks: Hinshaw et al., 1978; cats: Loss and Marra, 2017). Among mammalian invaders, domestic carnivores, e.g., dogs (Canis familiaris) and cats (Felis catus), are reported to exert the most serious damage (Van't Woudt, 1990; Doherty et al., 2016; Home et al., 2017). Furthermore, their management is challenging because of their association with humans and their consequent appeal to the public (Green and Gipson, 1994; Natoli, 1994; Thomas et al., 2013). Negative impacts of free-ranging dogs are well-known and commonly accepted to occur by the general public (Young et al., 2011; Hughes and Macdonald, 2013), as dogs may also attack humans (Scott and Causey, 1973; Home et al., 2017), whereas negative impacts by domestic cats are often denied or justified by the public as a form of "natural predatory instinct" (Hall et al., 2016).

Across the globe, the domestic cat, Felis catus, is the most popular pet. The Ecology Global Network estimates that there are 600 million-1 billion domestic cats in the world, including pets (i.e., largely dependent on human-provided food), strays/homeless (i.e., poorly dependent on human-provided food), and feral cats (totally independent from humans), throughout all of the continents except for Antarctica (www. ecology.com). The behavioral and physiological plasticity of domestic cats allows them to survive even without food provided by humans, both in urban areas and natural environments (Gillies, 2001; Harper, 2005; Cove et al., 2018). Most studies on the ecological impacts of domestic cats have been conducted in island ecosystems (Liberg, 1984; Woods et al., 2003; Bonnaud et al., 2011; Medina et al., 2011), where domestic cats are responsible for the decline of many seabirds (Keitt et al., 2002; Hughes et al., 2008; Bonnaud et al., 2009; Faulquier et al., 2009) and for the local extinction of other terrestrial vertebrates (Fitzgerald and Turner, 2000; Blackburn et al., 2004; Medina and Garcìa, 2007; Medina et al., 2011; Kutt, 2012). Free-ranging domestic cats may affect bird fecundity through non-lethal indirect effects, i.e., by increasing stress (Bonnington et al., 2013). An increase in prey species populations after cat removal from islands suggests that domestic cats represent a major source of predation in such ecosystems (Gillies, 2001; Hughes et al., 2008; Siracusa, 2010). Birò et al. (2005) found a low trophic niche overlap between feral cats and wild cats Felis silvestris, suggesting the occurrence of niche partitioning between the two. Conversely, domestic cats are opportunistic predators, therefore showing a selective advantage over wild cats, which are specialized to preying upon rodents (Birò et al., 2005; Széles et al., 2018). Moreover, house-based domestic cats are often free to move around outside and may increase the predatory pressure exerted on wildlife (Pearre and Maass, 1998). Domestic cats frequently kill wild animals without consuming them and frequently bring prey home as a "gift" to their owners (Meek, 1998; Woods et al., 2003). Unlike feral cats, house cats are provided with medical care and shelter by pet owners, so they are not subjected to fluctuations in prey abundances and are therefore able to surpass the environmental carrying capacity (Woods et al., 2003; Tschanz et al., 2011). Furthermore, domestic cats may rapidly revert to the feral state, maintaining their populations without human food supply (Birò et al., 2005; Széles et al., 2018). The use of collars with a bell has been reported to be a useful method for reducing wildlife killing by domestic cats (Calver et al., 2007; Gordon et al., 2010). Given the impacts detected in areas relatively poor in biodiversity (e.g., 1.4-3.7 billion birds and 6.9-20.7 billion mammals killed per year in the continental USA: Loss et al., 2013), an even stronger effect may be expected for biodiversity hotspot areas (cf. Home et al., 2017) such as the Mediterranean basin (Myers et al., 2000). Within this area, Italy hosts the highest animal species richness (Oosterbroek, 1994; Maiorano et al., 2007) as well as a high domestic cat density (nearly 10 million domestic cats: https:// pets.thenest.com; accessed on 7th April 2018), and yet evidence of the effects of cats on wildlife is still poorly documented (Siracusa, 2010; Ancillotto et al., 2013).

Traditionally, ecologists have studied the relationships between the severity of impacts of invasive species and the taxonomic structure of animal communities (e.g., Sanders et al., 2003; Hejda et al., 2009). Recent advances in the application of frameworks based on species traits have provided an alternative approach that allows researchers to quantify responses to disturbances across taxa and ecosystems (Oliver et al., 2015). Quantifying the impacts of invasive species on the functional structure of communities is important for elucidating the mechanism underpinning invasion processes, as well as for improving researchers' ability to predict the impacts of invasive species on ecosystem functioning (Tilman et al., 1997).

In this work, we conducted a citizen science study to assess the impact of domestic cat predation on the functional structure of vertebrate communities in Italy by using a trait-based approach. Specifically, the aims of this study were to (i) quantify the predatory pressure of domestic cats on vertebrate prey in relation to landscape features, and (ii) assess the effect of cat predation on the functional structure of vertebrate communities. We suggested that the highest number of species killed by free-roaming cats would occur in countryside areas and in southern regions, where the highest species richness is known to occur (Blasi et al., 2014; Genovesi et al., 2014). Moreover, we also predicted that, given the results of previous studies, cats with a bell on their collars (Calver 


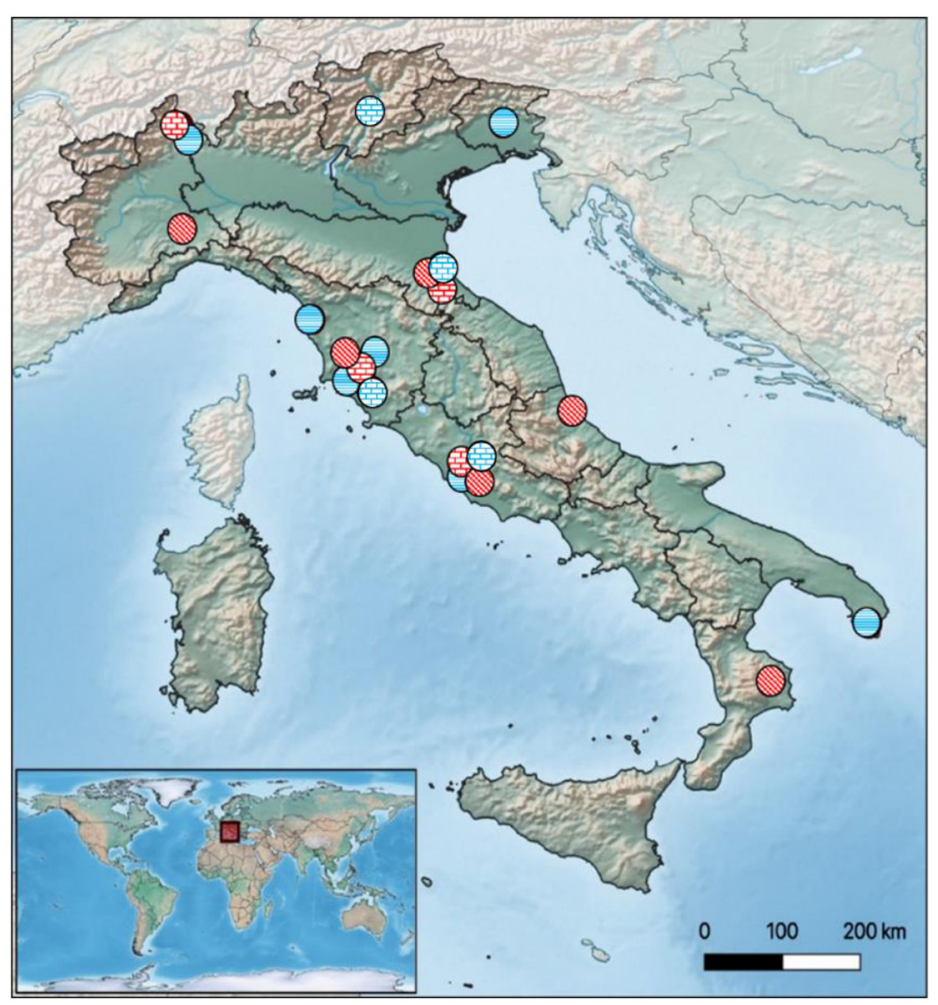

$$
\begin{aligned}
& \text { = male cat near countryside } \\
& =\text { male cat far from countryside } \\
& =\text { female cat near countryside } \\
& \text { = female cat far from countryside }
\end{aligned}
$$

FIGURE 1 | Locations of 21 cat owners who monitored the prey their cats returned over the course of 1 year (January-December 2016).

et al., 2007; Gordon et al., 2010) would kill fewer individuals and species than those without bells.

\section{MATERIALS AND METHODS}

\section{Citizen Science Survey}

We carried out a citizen science survey to collect data on wild species killed by domestic cats. The project was advertised through mailing lists ("Italian vertebrates": vertebrati@liste.cilea.it), specific Facebook groups dealing with wildlife in Italy (Table S1), flyers in universities (Pisa, Siena, Florence, Rome, Milan, Turin, Pavia, and Catania), wildlife agencies, catteries, and human meeting places. The survey was also conducted using online platforms and social networks (Facebook, Twitter) to gather information about domestic cat predation on wildlife in Italy. In detail, participants were asked to provide us with photographs of predation by their domestic cats, with collection between 2014 and 2017. The project was launched in spring 2014 and kept open until the end of 2017: only data supported by photographs and attached coordinates were kept for analyses. We did not ask for any further information from the cat owners to avoid privacy issues. Environmental variables were obtained by plotting coordinates on satellite maps. We also followed up with targeted questions to contributors to increase the reliability and adequacy of our survey (cf. Home et al., 2017).

Among the surveyed cat owners, we recruited a total of 21 volunteers (Figure 1) through Facebook groups, listed in
Table S1, to monitor predation events by single cats throughout 1 year (January-December 2016) by recording and photographing all prey items brought home by the owned cat. These data were also added to the citizen science project described above. The owners of the 21 cats also gave us information on their cats, including sex, use of collars with bells, and average period of outdoor access (hours/day: cf. Frank et al., 2016).

Prey species were grouped according to the International Union for the Conservation of Nature (IUCN) Red List (www. iucnredlist.org; accessed on 11.02.2019) and the Italian Red List (Rondinini et al., 2013).

\section{Data Analysis on the Citizen Science Survey}

This analysis was carried out on the killings by the 21 cats followed for one year (Table S2, corrected). Comparing functional diversity along different ecological gradients of disturbances would make strong inference about impact of cat predation on the functional structure of vertebrate communities, but this is not feasible with citizen science data collected for the 21 cats in this study. Functional diversity can be quantified in several ways, with a myriad of functional diversity indices, not only based on functional distances in multivariate space. Some metrics were developed to quantify community assembly processes. Metrics such as functional richness, have been shown to correlate very well with ecosystem processes (Tilman et al., 1997 and references thereof). 
Portions of functional space occupied by different classes were compared using a convex hull approach. The convex hull is the minimum convex geometry that includes all the observations considered (Preparata and Shamos, 1985) and has recently been proposed as a method for representing the volume of functional space used by a community (Villéger et al., 2008). For each prey class, we calculated the area of each convex hull. All the analyses were carried in the software $\mathrm{R}$ (version 3.5.1., $\mathrm{R}$ Foundation for Statistical Computing, Wien, Austria). The ape package was used to perform the Principal Coordinate Analysis. The code developed has been uploaded to a dedicated github repository (https://github.com/drmarcogir/cats).

\section{Variables Influencing Predation Rate by Domestic Cats}

We assessed the effect of five variables on the killing rate (i.e., number of prey brought home) by the 21 domestic cats that were intensively monitored for 1 year through mixed effect models computed in the R (version 3.5.1., R Foundation for Statistical Computing, Wien, Austria) packages lme4 (Bates et al., 2014) and MuMIn (Barton and Barton, 2015). The variables included in the models were: latitude, distance from the countryside (measured as the minimum distance from the house of the cat owner and the border of human settlements, i.e., where the number of houses inhabited by humans was $<2 / 100 \mathrm{~m}^{2}$ ), duration of cat outdoor activity (hours/day), presence/absence of a collar with a bell $(1=$ present; $2=$ absent $)$, and sex $(1=$ male; $2=$ female). Bioclimatic ecoregions (cf. Blasi et al., 2014; Genovesi et al., 2014) were included in the model as a random factor. Before running the model, we tested for multicollinearity among variables (i.e., $r>|0.6|$ ); no collinearity was detected among our variables and, therefore, we included all of them in the total model. Non-significant variables were removed one at a time until the elimination of terms caused a significant increase in the residual deviance.

\section{RESULTS}

\section{Citizen Science Survey}

We collected a total of 2042 entries for free-ranging vertebrates killed by domestic cats (and 7 more killings of freshwater fish in confined environments) (minimum number of cats, $N=145$; number of owners, $N=125$ ) (Figure 2). Among those, 1,533 were killed in warm months (April-September). Our survey was conducted throughout Italy, with data originating from 377 locations, including rural and urban areas, from sea level to mountainous areas (Figure 2).

The prey killed belonged to at least 207 species (Table S3): $17.61 \%$ taxa (including fish, thus on the total list of Table S2) were classified as "Threatened" or "Near Threatened" by at least the Italian or the international IUCN Red Lists and $7.77 \%$ as "Data Deficient" or "Not Evalutated" species (Table 1; Table S3). Prey-species size ranged from 1 to 3 grams for juvenile amphibians to about $2 \mathrm{~kg}$ for subadult hares and pheasants.

As to the 21 domestic cats (included among the 145 previously cited) that were followed for 1 year, the

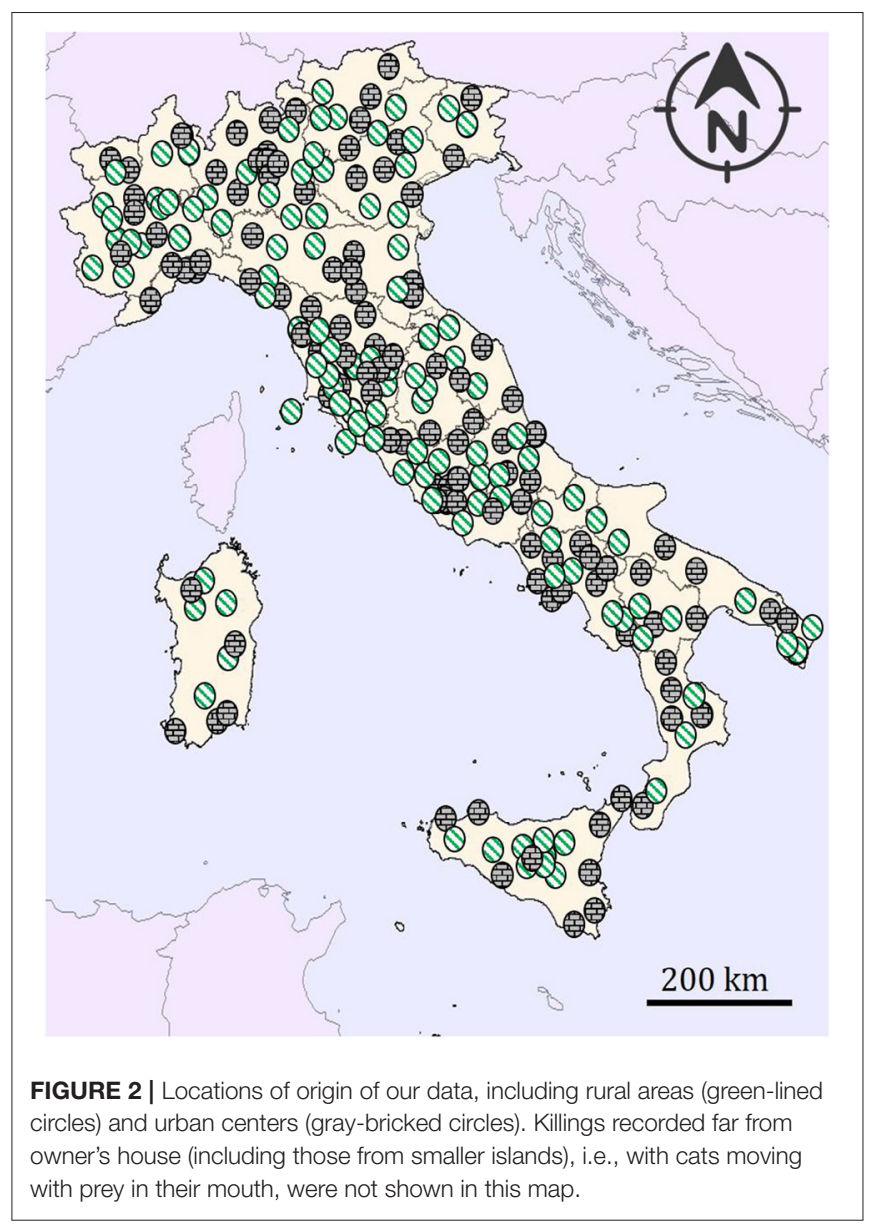

predation rate showed considerable variation within and among taxonomical classes. The most impacted classes were mammals ( $40 \%$ of killings), followed by birds (35\%), reptiles (21\%), and amphibians (4\%). Over $73 \%$ of predations occurred in spring and summer. A graphical summary of total and within-class predation frequencies is shown in Figure 3.

The most frequently killed species among mammals was the house mouse Mus domesticus (10\%), although Rattus rattus (9.4\%), Apodemus flavicollis (8.2\%), Sciurus vulgaris (8.2\%), and Suncus etruscus (8.2\%) were also reported many times: all of these species are common species ("Least Concern") in Italy (Rondinini et al., 2013). As to birds, the most frequently killed species were Turdus merula (13\%), Passer italiae (7.9\%), Streptopelia decaocto (7.9\%), and Sylvia atricapilla (7.9\%); P. italiae is endemic to Italy and is declining. In terms of reptiles, the most frequently killed species were Podarcis muralis (29\%), Hierophis virdiflavus/carbonarius (12.8\%), and Lacerta bilineata (12.8\%). Lastly, among amphibians, the most frequently killed species were Rana dalmatina (40\%) and Pelophylax synklepton esculentus (20\%), both listed within the annexes of the Habitat Directive. A summary of the proportion of species killed by these 21 cats revealed that two out of the total of 207 are of conservation concern (Figure 4): one amphibian and one bird species, Rana 
TABLE 1 | Near threatened, threatened, data deficient, and not evaluated prey species brought home by free-ranging domestic cats in Italy.

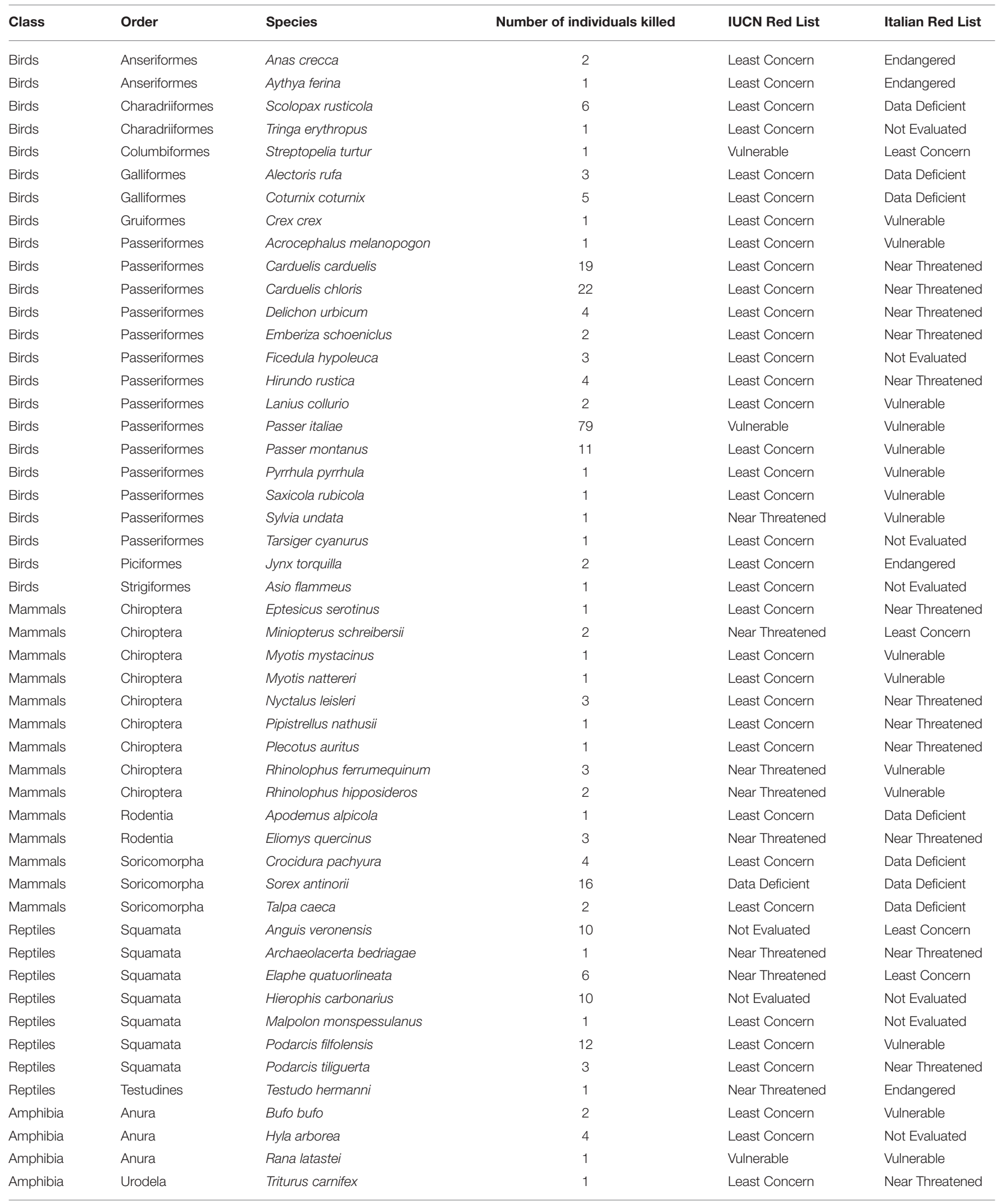

Predation rate by 21 cats followed for 1 year. 

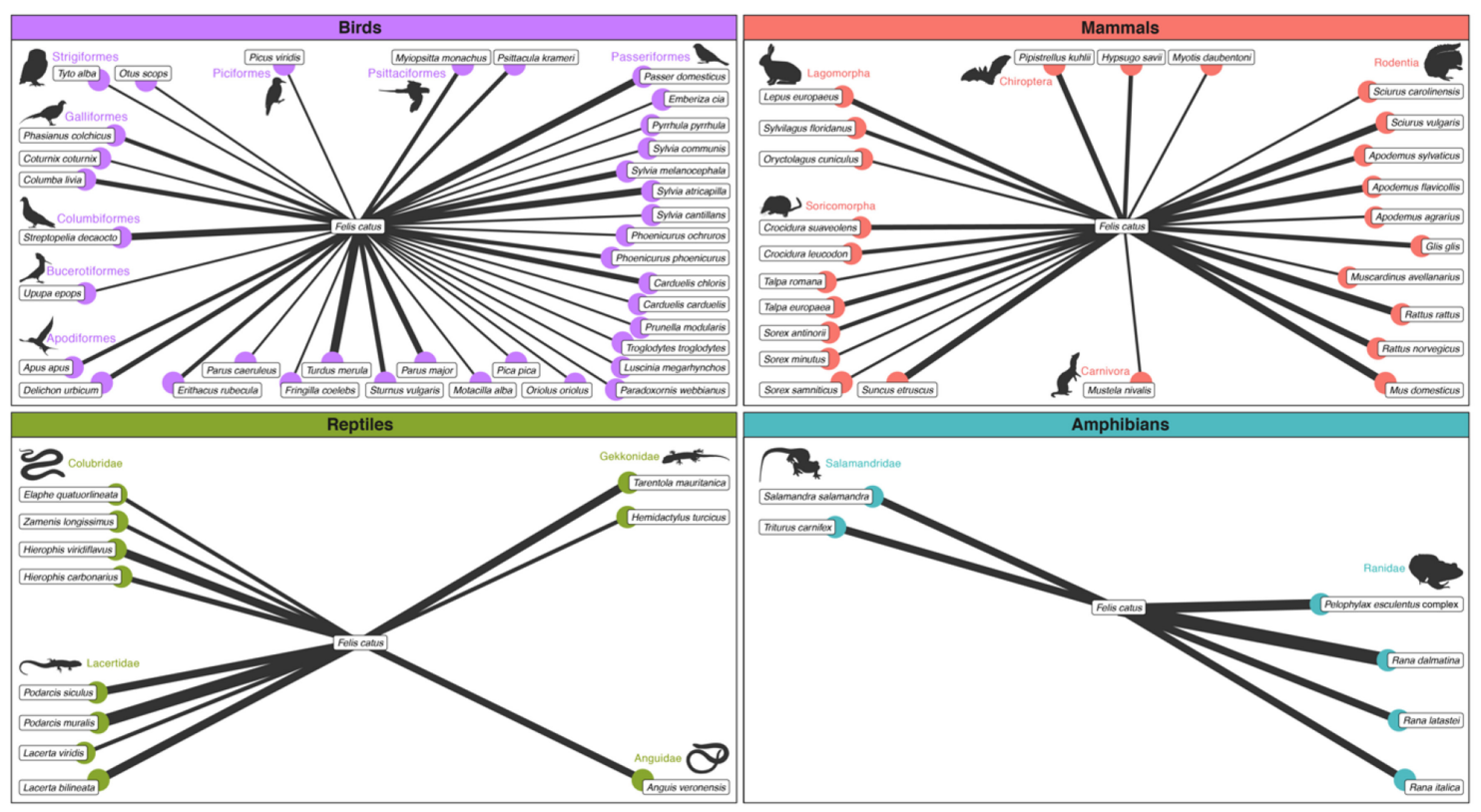

FIGURE 3 | Reported killings of 21 domestic cats for the following groups of vertebrates: birds, mammals, reptiles, and amphibians. The thickness of black lines represents the proportion of individuals of each killed species within each taxonomical class.

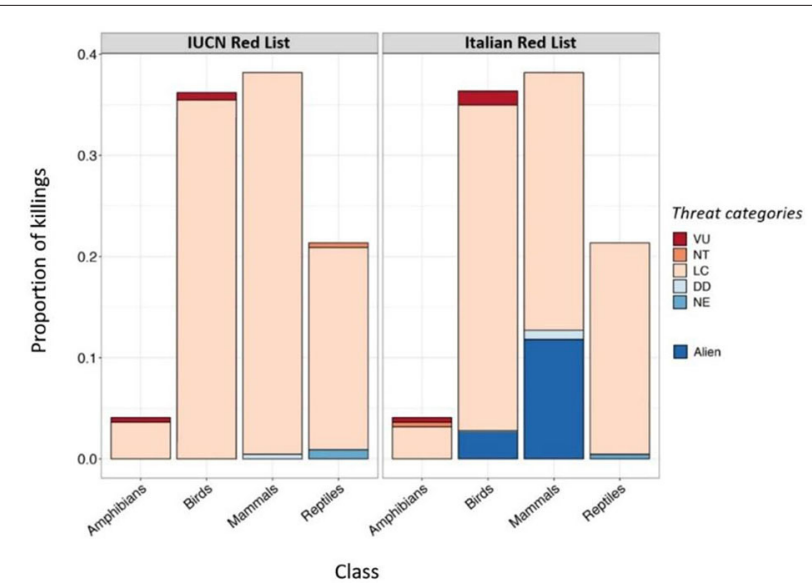

FIGURE 4 | Proportions of species killed by cats, grouped by threat categories. The two panels show different groupings according to the IUCN and Italian Red List species classifications. Legend codes indicate threat categories: VU, Vulnerable; NT, Near Threatened; LC, Least Concern; DD, Data Deficient; and NE, Not Evaluated. Alien species (i.e., those introduced to Italy) were not classified according to the Red List categories.

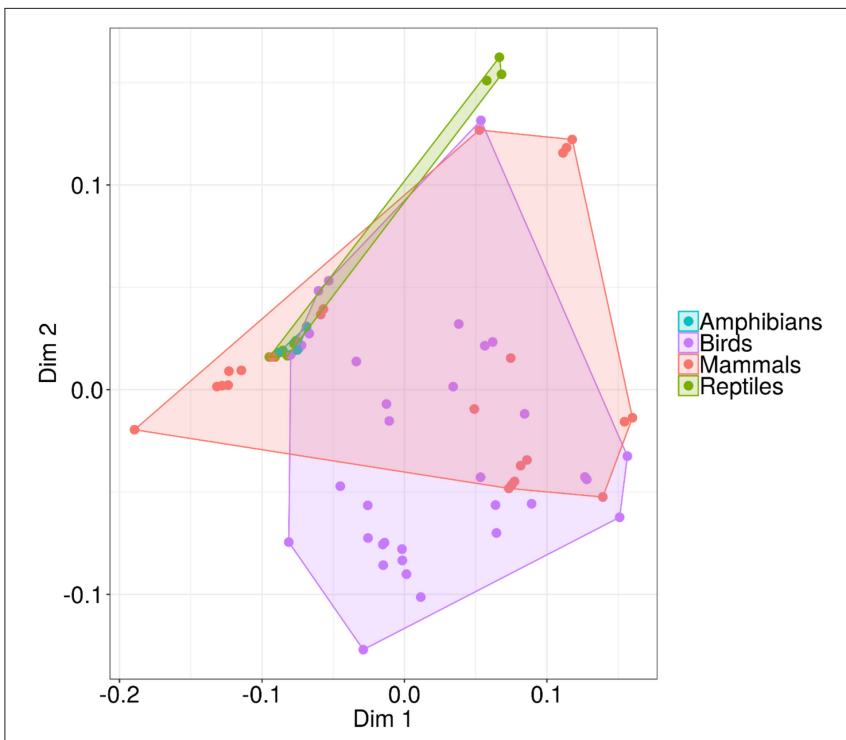

FIGURE 5 | Principal Coordinate Analysis (PCOA) performed on the trait matrix of killed species. The ordination shows the distribution of different species within trait space. Convex hulls, displayed in different colors, were calculated for each taxonomic class.

When examining the diet in functional trait space, PCoA analysis revealed that the class occupying the largest functional space was birds, followed by mammals, reptiles, and amphibians (Figure 5). Therefore, the largest impact was on the functional structure of mammal and bird assemblages. 
TABLE 2 | Factors affecting the number of prey items brought home by domestic cats in one year, estimated through a general linear model.

\begin{tabular}{lrcc}
\hline Variable & B & Standard error & $\boldsymbol{P}$ \\
\hline Distance from the countryside & -0.04 & 0.01 & $<0.001^{\text {** }}$ \\
Hours/day outside & 0.95 & 0.24 & $<0.001^{\text {** }}$ \\
Intercept & 46.28 & 7.98 & $0.02^{\star}$ \\
\hline
\end{tabular}

Asterisks indicate significant $P\left({ }^{*}<0.05 ;{ }^{* *}<0.001\right)$.

\section{Variables Influencing Killing Rates}

The predation rate of the 21 individual cats followed for 1 year increased with decreasing distance from the countryside and increasing number of hours of outside activity per day $\left(R^{2}=0.92\right.$ : Table 2; Tables S4, S5).

\section{DISCUSSION}

Evidence of the effects of cat predation on wildlife are rare for country-wide areas and generally comes from US urban and suburban ecosystems, which are relatively poor in biodiversity (e.g., Dunn and Tessaglia, 1993; Lepczyk et al., 2003; Loss et al., 2013; Loss and Marra, 2017). The few European country-wide studies on this topic are mostly taxon-specific (e.g., bats in Italy: Ancillotto et al., 2013, 2019; Siberian chipmunks: Mori et al., 2018). The only general study carried out in continental Europe (Poland) showed that free-ranging domestic cats mainly prey on wild mammals (Krauze-Gryz et al., 2012), but this study was limited to a very few rural areas. Conversely, our survey was conducted throughout Italy, both in rural areas and urban centers, from sea level to the mountains. The Mediterranean basin (i.e., northern Africa, the Middle East, and southern Europe, including the whole of Italy) is included in a biodiversity hotspot, i.e., one of the world's 36 biogeographic regions with significant levels of biodiversity, which is threatened by human activities (Noss et al., 2015). Introduced species, including feral ones, represent one of the main causes of biodiversity crisis, particularly in these areas (Wonham, 2006). Our analysis showed that at least 207 species, ranging in size from juvenile neometamorphosed frogs to adult weasels and hares, may be actively killed by free-ranging domestic cats. Over 30 of these are listed as "Threatened" by the International Red list, whereas the great majority (i.e., over 75\%) of species killed by free-ranging cats belong to the "Least Concern" category. This is consistent with the fact that Least Concern species are-on average-the most abundant species and thus potentially the most available to domestic cats, which are opportunistic predators (Loss and Marra, 2017). However, despite their widespread distribution and presence, these species may play key roles in the maintenance of other carnivore species deserving conservation measures, whose diet is based precisely on the species killed by domestic cats (e.g., Bertolino et al., 2015), and this may suggest a strong role for cat predations in ecosystem functioning. Moreover, the few reported kills of threatened species may be more deleterious than for many of the common widespread species. The Italian sparrow, Passer italiae, is endemic to Italy and is classified as "Vulnerable." The high predation rate by domestic cats on this bird may therefore be a threat to its conservation. Other endemic/near endemic Italian species that are highly preyed upon by domestic cats in Italy include the Valais shrew, Sorex antinorii, classified as "Data Deficient," the Sicilian shrew, Crocidura sicula, and the Italian slow worm, Anguis veronensis. Italy plays a key role in Europe in the conservation of the Eurasian red squirrel, Sciurus vulgaris, which is threatened by habitat fragmentation and competition with introduced species (Bertolino and Genovesi, 2003; Bertolino et al., 2015); this rodent is among the main species killed by domestic cats (i.e., over $8 \%$ predations). Moreover, we confirmed that free-roaming domestic cats may represent a huge threat to bat assemblages (Ancillotto et al., 2013), which include a number of imperiled species representing paramount bioindicators of environmental quality (Jones et al., 2009).

Free-ranging domestic cats may be active throughout the day and the night (Cove et al., 2018), therefore potentially affecting spatiotemporal behavior and the abundance of diurnal and nocturnal species (Parsons et al., 2018). Accordingly, the daily number of hours of a cat outside activity significantly increased the number of prey killed by cats. Furthermore, their home range size may exceed 10 hectares, even in urban areas (Pillay et al., 2018), and covering even larger areas in rural environments (up to 228 hectares, in male cats: Tschanz et al., 2011; Loss et al., 2013). Distance from the countryside was found to affect the number of prey items brought home by cats per year. This is in line with the longer distances traveled by freeranging cats in these areas. Conversely, we detected no effect of the local climatic ecoregion (cf. Blasi et al., 2014) nor of the sex of the cat on the predation rate, despite intersexual differences in hunting ability that occur in this species. Additionally, the presence of a bell on the collar of the cat was not effective in reducing wildlife killings, in contrast with anecdotal report by cat owners (unpublished data) and despite reports that, on islands, bells may reduce predations on birds (Calver et al., 2007; Gordon et al., 2010). Cat bibs are neoprene triangular pieces of brightly colored plastic material attached to cat collars that are used on free-roaming cats to warn possible prey of the presence of the cat, reducing their probability of being killed. However, although potentially functional in reducing predation, cat bibs did not eliminate predation on wildlife by domestic cats (van Heezik, 2010).

The wide ecological plasticity of domestic cats supports the fact that the domestic cat is on the " 100 of the world's worst invasive alien species" list, with populations increasing worldwide and in a huge variety of habitat types (Loss and Marra, 2017; Pillay et al., 2018). In this paper, we did not estimate the population abundance of killed species, so we cannot describe any impacts at the population level. However, we provided evidence that the strongest impact of domestic cats occurs at the functional structure level of mammal and bird assemblages (Lepczyk et al., 2003; Siracusa, 2010; Bonnington et al., 2013). Domestic cats are apex predators that show at least two reproductive peaks per year (Sogliani and Mori, 2019); thus, they may have few competitors (Castañeda et al., 2018; Sogliani and Mori, 2019) and may rapidly become the most abundant carnivorous species (Loss et al., 2013). Having 
population densities of all prey species throughout all study area would have allowed us to calculate killed prey selection, i.e., by comparing the total individual killed per species (i.e., the predation pressure) on the total population size for each species. Unfortunately, data on population density in the wild are limited particularly for small species such as reptiles, amphibians, nonmigrant small birds and small mammals. The largest database of vertebrate abundance (Santini et al., 2018) only includes estimates of population density for 41 species and in few localities per species: in Italy there are over 780 species of terrestrial vertebrates, many of which live in hundreds localities. We are aware that our dataset is far from being complete, as confirmed by other species killed by cats outside our sampling period (the little bittern in 2019; the Bechstein's bat in 2013: Ancillotto et al., 2013); moreover we sampled a limited percentage of Italian freeranging cats (and the number of prey killed by a cat in one year is only available for 21 cats). Therefore, as to the precautionary principle (Khayat et al., 2020), we are confident that impact occur particularly on K-strategy species (e.g., nocturnal mammals such as bats bats: Khayat et al., 2020) or species linked to transient habitats (e.g., Amphibians, crossing roads at night) and limited areas (e.g., islands), even if killed only occasionally. A high number of killings would also affect populations of Least Concern species, which represent indeed the majority of killings, possibly due to their abundance, particularly if exerted by a non-native predator such as the domestic cat. Further research is needed to assess the actual local effect at population levels.

Reducing the impacts of invasive species on wildlife requires eradication or at least reduction in population size through sterilization. Both of these strategies are often blocked by the general public, particularly when involving charismatic fauna (e.g., Bertolino and Genovesi, 2003; Crowley et al., 2017, 2018, 2019a). Reproduction control (i.e., sterilization) is reported to be a good way to control and manage urban populations of domestic cats, i.e., where human density is the highest and where eradication projects are mostly boycotted (Natoli et al., 2006). In rural areas, veterinarians who frequently deal with pet owners should encourage sterilization, using cat welfare as the main argument to convince cat owners (cf. Grayson and Calver, 2004). Sterilization would not prevent predation of wildlife by domestic cats, but it limits the number of offspring and thus the population size (Jones and Downs, 2011). For ethical reasons and considering the widespread denial of the negative impacts of domestic cats in western countries (Loss et al., 2018; Crowley et al., 2019b), lethal control would be challenging (Natoli et al., 2006; Thomas et al., 2013).

Citizen science has been proven to be effective in collecting data involving feral pets. Therefore, we suggest that it could be used as a tool to lead cat owners toward responsible ownership, e.g., through social media campaigns and public divulgation/discussion events in the main urban areas and meeting points. We strongly recommend cat owners to keep their pet cats indoors or, at least, limit their ranging bouts by avoiding nocturnal and crepuscular hours, particularly in warm months, i.e., when most wild species are active and in their reproductive periods. Together, the effectiveness of cat bibs for reducing predation on wildlife should be statistically tested (van Heezik, 2010). Field studies like this one may provide a scientific basis on which to build well-supported dissemination campaigns to fight against misinformation on this topic and, more generally, on the impacts of biological invasions (Natoli et al., 2006; Loss et al., 2018). However, scientific articles are unlikely to change the behavior of pet owners per se. Given the full-blown denial of the negative impacts of cats, which is also supported by published position papers (Lynn et al., 2019), the behavior of cat owners might be difficult to change, even in a biodiversity hotspot such as the Mediterranean basin. Cat welfare, including the increased risk of disease contraction in free-roaming individuals (Frenkel et al., 1970; Slater, 2004) and predation by wild carnivores (Sogliani and Mori, 2019), should thus be considered as effective methods to encourage cat owners to keep domestic cats under controlled conditions (McDonald et al., 2015). Laws state that it is a misdemeanor offense to not provide cats with adequate food, shelter, and freedom from pain, preventing cruelty but also promoting responsible cat ownership. Keeping cats indoors would help prevent damage to native wildlife and the spread of diseases and zoonoses from wild species to domestic cats. Increased inter- and intra-specific competition would increase cat stress: responsible owners should alleviate stress by reducing the encounters between cats and other species/individuals, as well as by taking care of their health status.

\section{DATA AVAILABILITY STATEMENT}

The datasets used for analysis in this study can be found in online repositories [https://github.com/drmarcogir/cats]. Photos, sensitive data and coordinates of owner's houses analyzed in this study are subject to the following licenses/restrictions [National Law 633/1941 and following integrations, DL 196/2003; General Data Protection Regulation - EU Regulation 2016/679] and cannot be shared also in line with assurance provided to citizen-scientists.

\section{AUTHOR CONTRIBUTIONS}

EM and MM: conceptualization. KT, AC, and LC: data collection. EM: supervision. MG: methodology. EM, MM, and MG: writing-original draft. All authors: review and editing.

\section{ACKNOWLEDGMENTS}

Authors would like to thank L. Ancillotto and all of the cat owners who provided data. We thank I. Kay-Lavelle, V. Sfondrini, and E. Bassett for language revision. Four reviewers and the Associate Editor, Franco Andreone, improved our first draft with their comments.

\section{SUPPLEMENTARY MATERIAL}

The Supplementary Material for this article can be found online at: https://www.frontiersin.org/articles/10.3389/fevo. 2019.00477/full\#supplementary-material 


\section{REFERENCES}

Ancillotto, L., Serangeli, M. T., and Russo, D. (2013). Curiosity killed the bat: domestic cats as bat predators. Mammal. Biol. 78, 369-373. doi: 10.1016/j.mambio.2013.01.003

Ancillotto, L., Venturi, G., and Russo, D. (2019). Presence of humans and domestic cats affects bat behaviour in an urban nursery of greater horseshoe bats (Rhinolophus ferrumequinum). Behav. Proc. 164, 4-9. doi: 10.1016/j.beproc.2019.04.003

Barton, K., and Barton, M. K. (2015). Package 'MuMIn'. $\mathrm{R}$ package version.

Bassi, E., Canu, A., Firmo, I., Mattioli, L., Scandura, M., and Apollonio, M. (2017). Trophic overlap between wolves and free-ranging wolf $\times$ dog hybrids in the Apennine Mountains, Italy. Glob. Ecol. Cons. 9, 39-49. doi: 10.1016/j.gecco.2016.11.002

Bates, D., Maechler, M., Bolker, B., and Walker, S. (2014). lme4: Linear mixed-effects models using Eigen and S4. $R$ Pack. Vers. 1, 1-23. doi: $10.18637 /$ jss.v067.i01

Bertolino, S., Colangelo, P., Mori, E., and Capizzi, D. (2015). Good for management, not for conservation: an overview of research, conservation and management of Italian small mammals. Hystrix 26, 25-35. doi: 10.4404/hystrix-26.1-10263

Bertolino, S., and Genovesi, P. (2003). Spread and attempted eradication of the grey squirrel (Sciurus carolinensis) in Italy, and consequences for the red squirrel (Sciurus vulgaris) in Eurasia. Biol. Cons. 109, 351-358. doi: 10.1016/S0006-3207(02)00161-1

Birò, Z., Lanszki, J., Szemethy, L., Heltai, M., and Randi, E. (2005). Feeding habits of feral domestic cats (Felis catus), wild cats (Felis silvestris) and their hybrids: trophic niche overlap among cat groups in Hungary. J. Zool. 266, 187-196. doi: 10.1017/S0952836905006771

Blackburn, T. M., Cassey, P., Duncan, R. P., Evans, K. L., and Gaston, K. J. (2004). Avian extinction and mammalian introductions on oceanic islands. Science 305, 1955-1958. doi: 10.1126/science.1101617

Blasi, C., Capotorti, G., Copiz, R., Guida, D., Mollo, B., Smiraglia, D., et al. (2014). Classification and mapping of the ecoregions of Italy. Plant Biosyst. 148, 1255-1345. doi: 10.1080/11263504.2014.985756

Boano, G., Perco, F., Pavia, M. and Baldaccini, N. E. (2019). Columba livia domestic breed, invasive entity also alien for Italy. Riv. Ital. Ornitol. 88, 3-10. doi: 10.4081/rio.2018.356

Bonnaud, E., Bourgeois, K., Vidal, E., Legrand, J., and Le Corre, M. (2009). How can the Yelkouan shearwater survive feral cat predation? A meta-population structure as a solution? Popul. Ecol. 51, 261-270. doi: 10.1007/s10144-008-0134-0

Bonnaud, E., Medina, F. M., Vidal, E., Nogales, M., Tershy, B., Zavaleta, E., et al. (2011). The diet of feral cats on islands: a review and a call for more studies. Biol. Invasions 13, 581-603. doi: 10.1007/s10530-010-9851-3

Bonnington, C., Gaston, K. J., and Evans, K. L. (2013). Fearing the feline: domestic cats reduce avian fecundity through trait-mediated indirect effects that increase nest predation by other species. J. Appl. Ecol. 50, 15-24. doi: 10.1111/1365-2664.12025

Calver, M., Thomas, S., Bradley, S., and McCutcheon, H. (2007). Reducing the rate of predation on wildlife by pet cats: the efficacy and practicability of collar-mounted pounce protectors. Biol. Cons. 137, 341-348. doi: 10.1016/j.biocon.2007.02.015

Carthey, A. J., and Banks, P. B. (2012). When does an alien become a native species? A vulnerable native mammal recognizes and responds to its long-term alien predator. PLOS ONE 7:e31804. doi: 10.1371/journal.pone. 0031804

Castañeda, I., Bellard, C., Jari,ć, I., Pisanu, B., Chapuis, J. L., and Bonnaud, E. (2018). Trophic patterns and home-range size of two generalist urban carnivores: a review. J. Zool. 307, 79-82. doi: 10.1111/jzo. 12623

Cilleros, K., Allard, L., Grenouillet, G., and Brosse, S. (2016). Taxonomic and functional diversity patterns reveal different processes shaping European and Amazonian stream fish assemblages. J. Biogeogr. 43, 1832-1843. doi: $10.1111 /$ jbi.12839

Cove, M. V., Gardner, B., Simons, T. R., Kays, R., and O'Connell, A. F. (2018). Free-ranging domestic cats (Felis catus) on public lands: estimating density, activity, and diet in the Florida Keys. Biol. Invasions 20, 333-344. doi: 10.1007/s10530-017-1534-x

Crowley, S. L., Cecchetti, M., and McDonald, R. A. (2019b). Hunting behaviour in domestic cats: an exploratory study of risk and responsibility among cat owners. People Nat. 1, 18-30 doi: 10.1002/pan3.6

Crowley, S. L., Hinchliffe, S., and McDonald, R. A. (2017). Invasive species management will benefit from social impact assessment. J. Appl. Ecol. 54, 351-357. doi: 10.1111/1365-2664.12817

Crowley, S. L., Hinchliffe, S., and McDonald, R. A. (2018). Killing squirrels: exploring motivations and practices of lethal wildlife management. Environ. Plann. E Nat. Space 1, 120-143. doi: 10.1177/2514848617747831

Crowley, S. L., Hinchliffe, S., and McDonald, R. A. (2019a). The Parakeet Protectors: understanding opposition to introduced species management. J. Env. Manage. 229, 120-132. doi: 10.1016/j.jenvman.2017.11.036

Davis, A. J., Huijbregts, H., and Krikken, J. (2000). The role of local and regional processes in shaping dung beetle communities in tropical forest plantations in Borneo. Glob. Ecol. Biogeog. 9, 281-292. doi: 10.1046/j.1365-2699.2000.00189.x

Davison, A., Birks, J. D. S., Griffiths, H. I., Kitchener, A. C., Biggins, D., and Butlin, R. K. (1999). Hybridization and the phylogenetic relationship between polecats and domestic ferrets in Britain. Biol. Cons. 87, 155-161. doi: 10.1016/S0006-3207(98)00067-6

Doherty, T. S., Dickman, C. R., Glen, A. S., Newsome, T. M., Nimmo, D. G., Ritchie, E. G., et al. (2017). The global impacts of domestic dogs on threatened vertebrates. Biol. Conserv. 210, 56-59. doi: 10.1016/j.biocon.2017.04.007

Doherty, T. S., Glen, A. S., Nimmo, D. G., Ritchie, E. G., and Dickman, C. R. (2016). Invasive predators and global biodiversity loss. Proc. Nat. Ac. Sci. U.S.A. 113, 11261-11265. doi: 10.1073/pnas.1602480113

Dunn, E. H., and Tessaglia, D. L. (1993). Predation of birds at feeders in winter. J. Field Ornithol. 65, 8-16.

Faulquier, L., Fontaine, R., Vidal, E., Salamolard, M., and Le Corre, M. (2009). Feral cats Felis catus threaten the endangered endemic Barau's petrel Pterodroma baraui at Reunion Island (Western Indian Ocean). Waterbirds 32, 330-336. doi: $10.1675 / 063.032 .0213$

Fitzgerald, B. M., and Turner, D. C. (2000). "Hunting behaviour of domestic cats and their impact on prey populations," in The Domestic Cat: The Biology of Its Behaviour, 2nd edn, eds D. C. Turner, and P. Bateson (Cambridge: Cambridge University Press), 148-171.

Flux, J. E. C., and Fullagar, P. J. (1992). World distribution of the Rabbit Oryctolagus cuniculus on islands. Mammal Rev. 22, 151-205. doi: 10.1111/j.1365-2907.1992.tb00129.x

Frank, A. S., Carthey, A. J., and Banks, P. B. (2016). Does historical coexistence with dingoes explain current avoidance of domestic dogs? Island bandicoots are naïve to dogs, unlike their mainland counterparts. PloS ONE 11:e0161447. doi: 10.1371/journal.pone.0161447

Frenkel, J. K., Dubey, J. P., and Miller, N. L. (1970). Toxoplasma gondii in cats: fecal stages identified as coccidian oocysts. Science 167, 893-896. doi: 10.1126/science.167.3919.893

Genovesi, P., Angelini, P., Duprè̀, E., Ercole, S., Giacanelli, V., Ronchi, F., et al. (2014). Specie ed habitat di interesse comunitario in Italia: Distribuzione, Stato di Conservazione e Trend. Roma: ISPRA, Serie Rapporti.

Gillies, C. (2001). Advances in New Zealand Mammalogy 1990-2000: house cat. J. Royal Soc. New Zeal. 31, 205-218. doi: 10.1080/03014223.2001.9517648

Gordon, J. K., Matthaei, C., and Van Heezik, Y. (2010). Belled collars reduce catch of domestic cats in New Zealand by half. Wildl. Res. 37, 372-378. doi: 10.1071/WR09127

Grayson, J., and Calver, M. C. (2004). Regulation of domestic cat ownership to protect urban wildlife: a justification based on the precautionary principle. Royal Zool. Soc. New South Wales 1, 169-178. doi: 10.7882/FS.2004.094

Green, J. S., and Gipson, P. S. (1994). "Feral dogs," in The handbook: Prevention and Control of Wildlife Damage, eds Internet Center for Wildlife Damage Management, 35, (Lincoln, NE: University of Nebraska Editions).

Hall, C. M., Adams, N. A., Bradley, J. S., Bryant, K. A., Davis, A. A., Dickman, C. R., et al. (2016). Community attitudes and practices of urban residents regarding predation by pet cats on wildlife: an international comparison. PLoS ONE 11:e0151962. doi: 10.1371/journal.pone.0151962

Harper, G.A. (2005). Numerical and functional response of feral cats (Felis catus) to variations in abundance of primary prey on Stewart Island (Rakiura), New Zealand. Wildl. Res. 32, 597-604. doi: 10.1071/WR04057 
Hejda, M., Pyšek, P., and Jarosik, V. (2009). Impact of invasive plants on the species richness, diversity and composition of invaded communities. J. Ecol. 97, 393-403. doi: 10.1111/j.1365-2745.2009.01480.x

Hinshaw, V. S., Webster, R. G., and Turner, B. (1978). Novel Influenza A viruses isolated from Canadian feral ducks: including strains antigenically related to swine influenza (Hsw1N1) viruses. J. Gen. Virol. 41, 115-127. doi: 10.1099/0022-1317-41-1-115

Home, C., Bhatnagar, Y. V., and Vanak, A. T. (2017). Canine Conundrum: domestic dogs as an invasive species and their impacts on wildlife in India. Anim. Cons. 21, 275-282. doi: 10.1111/acv.12389

Hughes, B. J., Martin, G. R., and Reynolds, S. J. (2008). Cats and seabirds: effects of feral domestic cat Felis silvestris catus eradication on the population of sooty terns Onychoprion fuscata on Ascension Island, South Atlantic. Ibis 150, 122-131. doi: 10.1111/j.1474-919X.2008.00838.x

Hughes, J., and Macdonald, D. W. (2013). A review of the interactions between free-roaming domestic dogs and wildlife. Biol. Cons. 157, 341-351. doi: 10.1016/j.biocon.2012.07.005

Jones, A. L., and Downs, C. T. (2011). Managing feral cats on a university's campuses: how many are there and is sterilization having an effect? J. Appl. Anim. Welfare Sci. 14, 304-320. doi: 10.1080/10888705.2011. 600186

Jones, G., Jacobs, D. S., Kunz, T. H., Willig, M. R., and Racey, P. A. (2009). Carpe noctem: the importance of bats as bioindicators. Endang. Spec. Res. 8, 93-115. doi: $10.3354 /$ esr00182

Keitt, B. S., Wilcox, C., Tershy, B. R., Croll, D. A., and Donlan, C. J. (2002). The effect of feral cats on the population viability of black-vented shearwaters (Puffinus opisthomelas) on Natividad Island, Mexico. Anim. Cons. 5, 217-223. doi: $10.1017 /$ S1367943002002263

Khayat, R. O. S., Grant, R. A., Ryan, H., Melling, L. M., Dougill, G., Killick, D. R., et al. (2020). Investigating cat predation as the cause of bat wing tears using forensic DNA analysis. Ecol. Evol. 10, 8368-8378. doi: 10.1002/ece3.6544

Krauze-Gryz, D., Gryz, J., and Goszczynski, J. (2012). Predation by domestic cats in rural areas of central Poland: an assessment based on two methods. J. Zool. 288, 260-266. doi: 10.1111/j.1469-7998.2012. 00950.x

Kutt, A. S. (2012). Feral cat (Felis catus) prey size and selectivity in northeastern Australia: implications for mammal conservation. J. Zool. 287, 292-300. doi: 10.1111/j.1469-7998.2012.00915.x

Lepczyk, C. A., Mertig, A. G., and Liu, J. (2003). Landowners and cat predation across rural-to-urban landscapes. Biol. Cons. 115, 191-201. doi: 10.1016/S0006-3207(03)00107-1

Liberg, O. (1984). Food habits and prey impact by feral and house-based domestic cats in a rural area in Southern Sweden. J. Mammal. 65, 424-432. doi: $10.2307 / 1381089$

Loss, S. R., and Marra, P. P. (2017). Population impacts of free-ranging domestic cats on mainland vertebrates. Front. Ecol. Environm. 15, 502-509. doi: $10.1002 /$ fee. 1633

Loss, S. R., Will, T., Longcore, T., and Marra, P. P. (2018). Responding to misinformation and criticisms regarding United States cat predation estimates. Biol. Invasions 20, 3385-3396. doi: 10.1007/s10530-0181796-y

Loss, S. R., Will, T., and Marra, P. P. (2013). The impact of free-ranging domestic cats on wildlife of the United States. Nat. Comm. 4:1936. doi: $10.1038 /$ ncomms 2380

Lynn, W. S., Santiago-Ávila, F., Lindenmayer, J., Hadidian, J., Wallach, A., and King, B. J. (2019). A moral panic over cats. Conserv. Biol. 33, 769-776. doi: $10.1111 /$ cobi.13346

Maiorano, L., Falcucci, A., Garton, E. O., and Boitani, L. (2007). Contribution of the Natura 2000 network to biodiversity conservation in Italy. Cons. Biol. 21, 1433-1444. doi: 10.1111/j.1523-1739.2007.00831.x

Malo, J. E., Acebes, P., Giannoni, S. M., and Traba, J. (2011). Feral livestock threatens landscapes dominated by columnar cacti. Acta Oecol. 37, 249-255. doi: 10.1016/j.actao.2011.02.008

Mazel, F., Wüest, R. O., Lessard, J. P., Renaud, J., Ficetola, G. F., Lavergne, S., et al. (2017). Global patterns of $\beta$-diversity along the phylogenetic time-scale: The role of climate and plate tectonics. Glob. Ecol. Biogeog. 26, 1211-1221. doi: $10.1111 /$ geb.12632
McDonald, J. L., Maclean, M., Evans, M. R., and Hodgson, D. J. (2015). Reconciling actual and perceived rates of predation by domestic cats. Ecol. Evol. 5, 2745-2753. doi: 10.1002/ece3.1553

Medina, F. M., Bonnaud, E., Vidal, E., Tershy, B. R., Zavaleta, E. S., Josh Donlan, C., et al. (2011). A global review of the impacts of invasive cats on island endangered vertebrates. Glob. Change Biol. 17, 3503-3510. doi: 10.1111/j.1365-2486.2011.02464.x

Medina, F. M., and Garcia, R. (2007). Predation of insects by feral cats (Felis silvestris catus L., 1758) on an oceanic island (La Palma, Canary Island). J. Insect Conserv. 11, 203-207. doi: 10.1007/s10841-006-9036-7

Meek, P. D. (1998). Food items brought home by domestic cats Felis catus (L) living in Booderee National Park, Jervis Bay. Proc. Linn. Soc. New South Wales $120,43-47$.

Mori, E., Zozzoli, R., and Menchetti, M. (2018). Global distribution and status of introduced Siberian chipmunks Eutamias sibiricus. Mammal Rev. 48, 139-152. doi: $10.1111 / \mathrm{mam} .12117$

Myers, N., Mittermeier, R. A., Mittermeier, C. G., Da Fonseca, G. A., and Kent, J. (2000). Biodiversity hotspots for conservation priorities. Nature 403, 853-858. doi: $10.1038 / 35002501$

Natoli, E. (1994). Urban feral cats (Felis catus L.): perspectives for a demographic control respecting the psycho-biological welfare of the species. Ann. Ist Sup. Sanità 30, 223-227.

Natoli, E., Marigliano, L., Cariola, G., Faini, A., Bonanni, R., Cafazzo, S., et al. (2006). Management of feral domestic cats in the urban environment of Rome (Italy). Prev. Vet. Med. 77, 180-185. doi: 10.1016/j.prevetmed.2006. 06.005

Noss, R. F., Platt, W. J., Sorrie, B. A., Weakley, A. S., Means, D. B., Costanza, J., et al. (2015). How global biodiversity hotspots may go unrecognized: lessons from the North American Coastal Plain. Divers. Distrib. 21, 236-244. doi: $10.1111 /$ ddi. 12278

Oliver, T. H., Heard, M. S., Isaac, N. J. B., Roy, D. B., Procter, D., Eigenbrod, F., et al. (2015). Biodiversity and resilience of ecosystem functions. Trends Ecol. Evol. 30, 673-684. doi: 10.1016/j.tree.2015.08.009

Oosterbroek, P. (1994). Biodiversity of the Mediterranean region. Syst. Assoc. $50,289-289$.

Parsons, M. H., Banks, P. B., Deutsch, M. A., and Munshi-South, J. (2018). Temporal and space-use changes by rats in response to predation by feral cats in an urban ecosystem. Front. Ecol. Evol. 6:146. doi: 10.3389/fevo.2018.00146

Pearre, S., and Maass, R. (1998). Trends in the prey size-based trophic niches of feral and house cats Felis catus L. Mammal Rev. 28, 125-139. doi: 10.1046/j.1365-2907.1998.00030.x

Pillay, K. R., Streicher, J., and Downs, C. T. (2018). Home range and habitat use of feral cats in an urban mosaic in Pietermaritzburg, KwaZulu-Natal, South Africa. Urb. Ecosyst. 5, 999-1009. doi: 10.1007/s11252-018-0766-6

Preparata, F. P., and Shamos, M. I. (1985). Computational geometry. Texts and Monographs in Computer Science. New York, NY: Springer-Verlag Editions. doi: 10.1007/978-1-4612-1098-6

Randi, E., Pierpaoli, M., Beaumont, M., Ragni, B., and Sforzi, A. (2001). Genetic identification of wild and domestic cats (Felis silvestris) and their hybrids using Bayesian clustering methods. Mol. Ecol. 17, 285-293. doi: 10.1111/j.1365-294X.2007.03417.x

Rondinini, C., Battistoni, A., Peronace, V., and Teofili, C. (2013). Lista Rossa IUCN dei Vertebrati Italiani. Rome: Comitato Italiano IUCN e Ministero dell'Ambiente e della Tutela del Territorio e del Mare.

Sanders, N. J., Gotelli, N. J., Heller, N. E., and Gordon, D. M. (2003). Community disassembly by an invasive species. Proc. Nat. Ac. Sci. U.S.A. 100, 2474-2477. doi: 10.1073/pnas.0437913100

Santini, L., Isaac, N.J., Maiorano, L., Ficetola, G.F., Huijbregts, M.A., Carbone, C., and Thuiller, W., (2018). Global drivers of population density in terrestrial vertebrates. Glob. Ecol. Biogeogr. 27, 968-979. doi: 10.1111/geb.12758

Scott, M. D., and Causey, K. (1973). Ecology of feral dogs in Alabama. J. Wildl. Manage. 37, 253-265. doi: 10.2307/3800116

Siracusa, A. M. (2010). Relazione tra una comunità di uccelli e densità di gatto domestico Felis silvestris catus in un'area urbana siciliana. Avocetta 34, 57-61.

Slater, M. R. (2004). Understanding issues and solutions for unowned, free-roaming cat populations. J. Am. Vet. Med. Assoc. 225, 1350-1354. doi: 10.2460/javma.2004.225.1350.1 
Sogliani, D., and Mori, E. (2019). "The Fox and the Cat": sometimes they do not agree. Mammal. Biol. 95: 150-154. doi: 10.1016/j.mambio.2018.07.003

Széles, G. L., Purger, J. J., Molnár, T., and Lanszki, J. (2018). Comparative analysis of the diet of feral and house cats and wildcat in Europe. Mammal Res. 63, 43-53. doi: 10.1007/s13364-017-0341-1

Thomas, R. L., Fellowes, M. D., and Baker, P. J. (2013). Spatio-temporal variation in predation by urban domestic cats (Felis catus) and the acceptability of possible management actions in the UK. PLoS ONE 7:e49369. doi: 10.1371/journal.pone.0049369

Tilman, D., Knops, J., Wedin, D., Reich, P., Ritchie, M., and Siemann, E. (1997). The influence of functional diversity and composition on ecosystem processes. Science 277, 1300-1302. doi: 10.1126/science.277.53 30.1300

Tschanz, B., Hegglin, D., Gloor, S., and Bontadina, F. (2011). Hunters and non-hunters: skewed predation rate by domestic cats in a rural village. Eur. J. Wildl. Res. 57, 597-602. doi: 10.1007/s10344-0100470-1

van Heezik, Y. (2010). Pussyfooting around the issue of cat predation in urban areas. Oryx 44, 153-154. doi: 10.1017/S003060531000027X

Van't Woudt, B. D. (1990). Roaming, stray, and feral domestic cats and dogs as wildlife problems. Proc. $14^{\text {th }}$ Vertebr. Pest Conf. 78, 291-295.

Villéger, S., Mason, N. W., and Mouillot, D. (2008). New multidimensional functional diversity indices for a multifaceted framework in functional ecology. Ecology 89, 2290-2301. doi: 10.1890/07-1206.1
Wonham, M. (2006). "Species invasions," in Principles of Conservation Biology, eds M. J. Groom, G. K. Meffe, and C. R. Carroll (Sunderland, MA: Sinauer Associates Editions), 209-227.

Woods, M., McDonald, R. A., and Harris, S. (2003). Predation of wildlife by domestic cats Felis catus in Great Britain. Mammal Rev. 33, 174-188. doi: 10.1046/j.1365-2907.2003.00017.x

Young, J. K., Olson, K. A., Reading, R. P., Amgalanbaatar, S., and Berger, J. (2011). Is wildlife going to the dogs? Impacts of feral and free-roaming dogs on wildlife populations. BioScience 61, 125-132. doi: 10.1525/bio.2011.61.2.7

Conflict of Interest: The authors declare that the research was conducted in the absence of any commercial or financial relationships that could be construed as a potential conflict of interest.

The reviewer GB declared a past co-authorship with one of the authors, EM to the handling editor.

Copyright (๑) 2019 Mori, Menchetti, Camporesi, Cavigioli, Tabarelli de Fatis and Girardello. This is an open-access article distributed under the terms of the Creative Commons Attribution License (CC BY). The use, distribution or reproduction in other forums is permitted, provided the original author(s) and the copyright owner(s) are credited and that the original publication in this journal is cited, in accordance with accepted academic practice. No use, distribution or reproduction is permitted which does not comply with these terms. 